\title{
Sharing is caring vs. stealing is wrong \\ A moral argument for limiting copyright protection
}

\author{
Julian Hauser \\ Graduate Student, \\ School of Philosophy, Psychology and Language Sciences, \\ University of Edinburgh, United Kingdom \\ julian@julianhauser.com
}

\begin{abstract}
Copyright is at the centre of both popular and academic debate. That emotions are running high is hardly surprising - copyright influences who contributes what to culture, how culture is used, and even the kind of persons we are and come to be. Consequentialist, Lockean, and personality interest accounts are generally advanced in the literature to morally justify copyright law. I critically discuss these and come to the conclusion that only very limited authorial control of works is morally justified: Lockean accounts (including Nozick's) fail to ground moral rights in intellectual creations. If one accepts that copyright is not the only means of remunerating authors, then neither public interests nor authorial personality interests justify more than a small subset of the rights accorded by copyright law. The pared-down version of copyright that I defend consists of the right to attribution, the right to have one's non-endorsement of modifications or uses of one's works explicitly noted, and the right to a share of the profit that may result from the commercial uses of one's works. Importantly, this last right must be implemented so that it does not grant the author the ability to boycott any uses. These rights hinder neither public nor authorial interests and advance at least one of the two. Additionally, I defend the importance of non-copyright compensation systems that ensure that authors are financially compensated for their valuable work. I also cursorily explore whether contribution to another person's authorial work gives rise to moral interests.
\end{abstract}

Keywords: copyright; intellectual property; applied ethics; digital rights; utilitarianism; Locke; Nozick; Hobbes; personality interests.

Reference to this paper should be made as follows: Julian Hauser (2016) 'Sharing is caring vs. stealing is wrong: A moral argument for limiting copyright protection', Int. J. Arts and Technology, Vol. ?, No. ?

Biographical notes: Julian Hauser is a $\mathrm{PhD}$ student of Philosophy at the University of Edinburgh, researching the mental and ethical implications of the use of modern information technology. He holds a BA in International Relations from the University of Geneva and an MA in Political, Legal, and Economic Philosophy from the University of Berne. This paper is a revised and condensed version of his MA thesis "Sharing is caring vs. stealing is wrong: An analysis of the moral justifications of copyright" (unpublished). 


\section{Introduction}

Interest in copyright has ebbed and flowed ever since its inception more than three hundred years ago. ${ }^{1}$ The debates brought on by the tidal wave of digitisation are however of a rare intensity. Copyright holders sue their own customers in the thousands. ${ }^{2}$ Authors decry the public's unwillingness to respect their "right to the protection of the moral and material interests resulting from [their work]" as set down in article 27 of the Universal Declaration of Human Rights. Others - consumers as well as authors - decry the culture industry's monopoly on human creativity; a worry about which the famous Twitter persona Nein succinctly tweeted: "Another beautiful day for the Culture Industry. For culture, not so much." ${ }^{\prime 3}$. Users of unlicensed copyrighted material are labelled pirates, a word that carries connotations of robbery, violence, and anarchy. In retaliation, the term been re-appropriated and users have gone on to found political parties that advance their views: the pirate parties. These parties see themselves as part of wider culture of collaborative creation and creative re-use, which finds copyright protection to be hindering their efforts of attaining a more cooperative, democratic, and "bottom-up" mode of production. ${ }^{4}$ Copyright, in short, is at the forefront of public discourse.

What was "once taken for granted as morally legitimate" 5 is now up for discussion. While balancing authorial with public interests is as essential today as it has been for centuries, computerisation and the internet present us with radically new ways of resolving this tension. The renewed debate on copyright has led to a decline in relative importance of the more technical matters of copyright law, benefiting fundamental discussions of the permissibility of copyright protection and the form and scope of a moral regulation of authorial works.

The literature on the ethics of copyright largely adheres to a distinction between three different approaches: a utilitarian approach (sometimes replaced by a value pluralist consequentialism), accounts based on the Lockean theory of labour desert, and lastly personality interest theories fashioned after Hegel (and sometimes Kant). ${ }^{6}$ A combination of two factors renders this separation problematic. Firstly, the approaches are presented as clearly distinct and stemming from fundamentally different streams of thought. While there is ample criticism of each individual approach, there is little research on the interactions between the different approaches. Secondly, only few philosophers argue that a single approach is sufficient to morally

\footnotetext{
${ }^{1}$ The enactment of the Statute of Anne in 1710 is generally seen as the origin of the modern notion of copyright.

${ }^{2}$ Kravets, D., 2008. File Sharing Lawsuits at a Crossroads, After 5 Years of RIAA Litigation. Wired.com. Available at: http://www.wired.com/2008/09/proving-file-sh/ [Accessed April 3, 2014].

${ }^{3}$ Nein, 2013. Another beautiful day for the culture industry. for culture, not so much. Twitter.com. Available at: https://twitter.com/NeinQuarterly/status/373772028069044224 [Accessed September 24, 2013].

${ }^{4}$ Aigrain, P., 2012. Sharing: Culture and the Economy in the Internet Age, Amsterdam: Amsterdam University Press.

${ }^{5}$ Himma, K.E., 2008. The Justification of Intellectual Property: Contemporary Philosophical Disputes. Journal of the American Society for Information Science and Technology, 59(7), pp.1143-1161, p.1143.

${ }^{6}$ For examples of this separation see Moore or Hughes. Moore, A., 2008. Personality-Based, RuleUtilitarian, and Lockean Justifications of Intellectual Property. In K. E. Himma \& H. Tavani, eds. The Handbook of Information and Computer Ethics. Hoboken, NJ: Wiley, pp. 105-130. Hughes, J., 1988. The Philosophy of Intellectual Property. Georgetown Law Journal, 77, pp.287-366.
} 
justify copyright. ${ }^{7}$ Most proponents of copyright think a combination of the three arguments can compensate for their individual weaknesses. However, while an approach focusing on the different accounts individually might be suited to show what speaks for each approach per se, it does not lend itself to the establishment of a general account of the morality of copyright.

In this paper I try to sketch a big picture account of the morality of copyright, analysing the key strengths and weaknesses of the various approaches. I hope to show that the case for copyright is far weaker than often assumed and that a weighing of the different interests is more likely to come out in favour of a substantially reduced set of rights for authors. I propose a set of rights that I believe is in accordance with the moral interests at stake.

In the next section I will set down the basic principles of copyright law, in section three I analyse public interests, in section four Lockean approaches, and in section five personality interest accounts. Section six investigates what rights these interests give rise to, section seven looks at contributors, and the last section concludes.

\section{Copyright law}

Arguments for and against copyright suffer from a notorious problem - there is no single thing called copyright. In fact, there exists not only a myriad of currently existing legal systems but also a spade of previously prevalent systems and of course an abundance of theoretically possible systems. And they all have a claim to the term copyright. ${ }^{8}$ In the following I define a minimal copyright system: a system exhibiting a number of principles that are defined in international law or present in (almost) all jurisdictions. ${ }^{9}$

The purpose of this exercise is to force the moving target that copyright is to hold still. A successful attack on the minimal copyright system does not necessarily imply that all copyright systems are morally unjustified - additional principles could still improve copyright's lot. However, by showing that copyright is morally problematic at its core, I hope to show that it is unlikely to be rescued by additional ad-hoc principles. Defining the basic principles should also help us pinpoint exactly where copyright goes wrong and what features a non-copyright regulation of authorial works might have. I want to stress that I have no interest in semantic squabbles - if you think the principles I define towards the end of this paper constitute copyright, then so be it.

\footnotetext{
${ }^{7}$ Resnik, D.B., 2003. A Pluralistic Account of Intellectual Property. Journal of Business Ethics, 46(4), pp.319-335.

${ }^{8}$ Even though I will be using the Anglo-Saxon term copyright throughout this paper, I do not mean to thereby exclude systems employing a different terminology (e.g. droit d'auteur). The applicability of my argument is limited only by the definition contained in this section.

${ }^{9}$ The most important and widely ratified international treaties on copyright are the Berne Convention for the Protection of Literary and Artistic (Berne Convention) from 1886 (last revision in 1971), the International Convention for the Protection of Performers, Producers of Phonograms and Broadcasting Organizations (Rome Convention) from 1961, and the Agreement on Trade-Related Aspects of Intellectual Property Rights (TRIPS) from 1994.
} 
In order to define the minimal copyright system two aspects need to be explored: (a) the subject matter of copyright and (b) the rights granted by copyright. The subject matter defines to which works copyright applies, whereas the rights granted define the bundle of rights accorded to the author of such works.

The scope of the subject matter of copyright is very wide. The Berne Convention defines as copyrightable every type of "production in the literary, scientific and artistic domain, whatever may be the mode or form of its expression". ${ }^{10}$ The argument that I develop in this paper applies to everything that is copyrightable: texts, movies, songs, sculptures, paintings, photographs, software and much more. Most countries rely on the concept of originality to determine whether a certain work is protected by copyright. ${ }^{11}$ Originality is a concept "fiendishly difficult to define" 12 but this need not concern us; at this point it is enough to understand that in today's copyright law originality requires that a work of authorship exhibit a minimal level of creativity. ${ }^{13}$

Minimal degree of creativity: copyrightable works need to exhibit a minimal degree of creativity.

The notion of expression is also essential to any conception of copyright. Only expressions are copyrightable, thereby excluding ideas, methods, functions and facts from being the subject of copyright. ${ }^{14}$ This can be illustrated by the fact that only the text of a book can be copyrighted but not the ideas expressed therein.

Idea/expression dichotomy: only expressions are copyrightable.

When it comes to the rights accorded by copyright, the matter is complicated by the fact that there are economic rights as well as moral rights. In most jurisdictions moral rights are considered a separate body of rights or might not exist at all.

Economic rights can be transferred and are thus tradable on the market. Historically, the right to make copies was the first such right. To this right many more have been added since, for example the right to modify a work, the right to communicate a work to the public, and more. I focus on the three rights I have just explicitly mentioned as they are the most basic. However, I believe my argument applies to all existing economic rights, and as such a different selection of minimal economic rights should not affect my assertions.

Minimal economic rights: copyright protects for a limited amount of time one or more of the following transferable rights: the right to make and

\footnotetext{
${ }^{10}$ Cited in : Dutfield, G., 2008. Global Intellectual Property Law, Cheltenham, UK: Edward Elgar, p.78.

${ }^{11}$ Abbott, F.M., Cottier, T. \& Gurry, F., 2011. International Intellectual Property in an Integrated World Economy 2nd ed., New York: Wolters Kluwer Law \& Business.

${ }^{12}$ Dutfield. Global Intellectual Property Law, op. cit., p.79.

${ }^{13}$ I do not intend to exclude systems that use a standard different from, but similar to, creativity. My notion of creativity should be seen as very thin and encompassing the US American legal notion of creativity, British copyrightability notions of skill and judgement as well as the continental European concepts of creative choice, intellectual contribution and again creativity.

${ }^{14}$ Abbott et al. International Intellectual Property in an Integrated World Economy, op. cit.
} 
distribute copies, the right to communicate a work to the public, and the right to make modifications.

Only economic rights are part of my definition of the minimal copyright system as moral rights only exist in some jurisdictions and always in addition to economic rights. Moral rights cannot usually be transferred and may hold in perpetuity. My criticism of copyright applies to most moral rights, too. While I retain the right of attribution - the right to be named as the author of one's works - I do argue against the second important moral right: the right of integrity. This right allows authors to object to modifications of their works that endanger their reputation.

Both economic and moral rights are held by the author alone; she can exclude anyone from using or appropriating her works. Non-authors do not enjoy any of the copyrights, except if these are transferred to them by the author.

Exclusivity: economic and moral rights must be exclusive to the author.

\section{Public interest arguments}

Our lives are inextricably intertwined with copyrighted works, used daily by probably a majority of the human population. We listen to music, read books, use word processors to write academic papers, consult written manuals, and go to the cinema. I believe it is reasonable to assume that the use of copyrighted works increases our welfare - why would people go to such lengths and incur such costs to acquire them otherwise? According to the public interest view, it is this increase in welfare that justifies copyright. It is not because of authors but because of the general public that we need to protect authors.

The argument can be summarised as follows: Copyright allows authors to use the power of the law to exclude people from using their works. This enables authors to gain financially from the sale of of their copyright or of copies of their works. Because of these financial incentives authors produce a higher volume or higher quality of works, and the public benefits from these works because authors will - for a fee - grant access to them. The negative effects of the fee barring some people from accessing the works they desire is counterbalanced by the positive effect on those users who have access to works that would not have come into existence without copyright. $^{15}$

I now turn to the plausibility of the premises necessary for the validity of the above argument. I have organised these into three groups. The first group is the most obvious and is considered by most welfare-based accounts and by my argument sketched above. The second is a necessary but often forgotten addition to the welfarist approach and the third goes beyond welfare and considers additional public interests.

The need for the first three premises should be clear from my description of

\footnotetext{
${ }^{15}$ Furthermore, to minimise the negative effects on those who are not able to use copyrighted works, most regulatory systems provide for exceptions to the rights they grant. Sometimes called fair use or limitations and exceptions, these aim to ensure that the public does not suffer unduly high costs and that authors do not misuse their powers. Dutfield. Global Intellectual Property Law, op. cit.
} 
the welfarist argument.

(C1) Copyright enables authors to benefit financially from their works.

(C2) Potential financial benefit acts as an incentive to authors to produce a higher quantity or quality of authorial works.

(C3) The consumer and producer benefits caused by copyright outweigh the consumer and producer harm.

Does copyright enable financial profit for authors as stated in (C1)? Copyright restores excludability and thus enables authors to ask for and receive monetary compensation for access to their works. In many economic sectors there is little doubt that copyright does benefit authors tremendously. However, in other sectors there exist powerful middle men who can siphon off the profits. For instance, only twelve percent of musicians' income in the United States derives directly from copyright with the highest earners taking home most of the share. ${ }^{16}$ Where authors do not currently profit from copyright, it can be argued that this not because of copyright per se. If the market mechanisms were to be relevantly regulated, it might be possible to correct the current power differentials between authors and content providers. In conclusion, copyright does enable at least some authors to benefit financially from their works. However, the real benefit must be critically assessed, taking into consideration that many authors do not benefit financially - or only benefit marginally - from copyright.

I believe two things are clear when it comes to premise (C2): Firstly, authorial works are not created for pecuniary gain alone. Many authors do not profit from copyright but produce works regardless. ${ }^{17}$ Secondly, financial gain has an incentivising effect on many producers. ${ }^{18}$ The precise role monetary and nonmonetary incentives play in the production of a specific work depends both on the author as well as the work's characteristics. However, it is clear that financial benefits do act as incentives for at least some authors. And because it is potential financial benefits that incentivise authors, copyright can be effective also when only few authors profit in practice. I therefore sustain premise $(\mathrm{C} 2)$.

Premise (C3) is where the economic calculus becomes complex indeed. A first step in appraising (C3) consists in adding the consumer and producer surplus achieved by a higher quantity and quality of authorial works. The uncertainties regarding $(\mathrm{C} 1)$ and $(\mathrm{C} 2)$ have already shown some of this task's difficulties. Additionally, we need to

\footnotetext{
${ }^{16}$ DiCola, P., 2013. Money from Music: Survey Evidence on Musicians’ Revenue and Lessons about Copyright Incentives. Arizona Law Review, 55, p.301.

${ }^{17}$ This points elicits more scepticism than I think it deserves. Many authors derive their income from non-copyright sources (e.g. programmers working with open source software), explicitly forgo copyright protection (e.g. artists using Creative Commons licenses), or simply do not earn money - or only very little - from the copyright in their works. See for example: Kretschmer, M. \& Hardwick, P., 2007. Authors' earnings from copyright and non-copyright sources: A survey of 25,000 British and German writers, Poole, UK: Centre for Intellectual Property Policy \& Management.

${ }^{18}$ Douglas, G. et al., 1998. Are Financial Incentives Related to Performance? A Meta-Analytic Review of Empirical Research. Journal of Applied Psychology, 83(5), pp.777-787. Ryan, R.M. \& Deci, E.L., 2000. Intrinsic and Extrinsic Motivations: Classic Definitions and New Directions. Contemporary Educational Psychology, 25(1), pp.54-67.
} 
factor in the costs caused by higher prices - these entail that people who would have benefited from access to authorial works that would have been produced even without copyright and who do not have the financial means to pay for them are left with less welfare with copyright than without. Furthermore, costs of legislation and enforcement need to be considered. There is also evidence that some forms of monetary incentives crowd out non-monetary incentives, which if true for authorial works, means the positive effects of copyright on the monetary incentives postulated in premise $(\mathrm{C} 2)$ are counteracted by negative effects on other forms of incentives. ${ }^{19}$ Additionally, producers themselves can be harmed by copyright when they desire to base their works on prior and copyrighted works. The empirical debate about this calculus has raged for a very long time, and there has so far been no comprehensive victory for either side. ${ }^{20}$ We are thus left in empirical limbo with regard to this premise.

The challenges faced by the public interest theorist are formidable when considering premises $(\mathrm{C} 1),(\mathrm{C} 2)$, and $(\mathrm{C} 3)$. And, to make matters worse, the proponent of copyright needs to supplement these premises with:

(C4) The welfare calculus of alternative compensation systems is worse than copyright's.

Premise (C4) is necessary because copyright is not the only means by which the production of authorial works can be financially incentivised. This premise often remains hidden and its truth assumed when the usefulness of copyright is, for instance, demonstrated with copyright's contribution to GDP. Possible implementations of alternative compensation systems are currently hotly debated in the field of economics. ${ }^{21}$ These schemes can be divided into two groups: compulsory government-mandated contribution schemes and voluntary contribution schemes. Both have their advantages and disadvantages, and a non-copyright system might also use a combination of some of these schemes to provide effective monetary incentives. What is more, an alternative system need not necessarily be as effective at providing monetary incentives as the copyright system. If the costs associated with such an alternative system are lower than in the copyright system, then this has to be factored in, too. What is more, already today not all monetary incentives to authors are due to copyright. It must also be noted that the less clear premises $(\mathrm{C} 1),(\mathrm{C} 2)$, and $(\mathrm{C} 3)$ work in copyright's favour, the more difficult it becomes to argue that (C4) is true.

There is clearly no consensus among economists on whether copyright is the best way to boost the production of authorial works. However, if anything, there is a tendency of doubt about copyright's usefulness. Moore - referring to the work of Machlup, Priest, and Long - writes: "Economists who have considered the question indicate that either the jury is out, or that other arrangements [than copyright] would be better". ${ }^{22}$ Even if I cannot conclusively reject the truth of premise (C4), it is clear that the proponent of copyright has a lot of work to do to turn it into an argument that

\footnotetext{
${ }^{19}$ Moore. Personality-Based, Rule-Utilitarian, and Lockean Justifications of Intellectual Property, op. cit.

${ }^{20}$ Abbott et al. International Intellectual Property in an Integrated World Economy, op. cit.

${ }^{21}$ Liebowitz, S.J. \& Watt, R., 2006. How to Best Ensure Remuneration for Creators in the Market for Music? Copyright and Its Alternatives. Journal of Economic Surveys, 20(4), pp.513-545.
} 
can lend strength to her point of view.

Finally, the welfare economic argument needs to fend off two additional attacks. Firstly, market relations might not be the only relevant way in which one can analyse welfare. Secondly, there might be values other than welfare that are important in assessing what policies are good for individuals and society. The first argument is about how to measure welfare and says that, for instance, power relations and nonmarket factors need to be considered, too. The second argument proposes a valuepluralist account.

(C5) The overall effect on the attainment of moral values is better in the copyright system than in all other regulatory system.

Under the above premise it remains possible to claim that we should only strive for economic welfare, but now an argument for such a claim must be supplied. I will content myself with supplying some hints about why such an argument is difficult, and why value-pluralism makes the argument for copyright even more onerous. For example, utilitarianism does not consider the importance of the diversity of works for people's ability of self-expression and personal development. There are indications that the top-down distribution symptomatic of a culture industry based on copyright reduces diversity. ${ }^{23}$ Another point is made by Gillespie, who writes that "[c]opyright is at the heart of cultural policy - those rules that help to govern what is said, by whom, and with what effect". ${ }^{24}$ With copyright, authors, copyright holders, and the financially well-off have a favoured access to works and are thus in a privileged position when it comes to deciding on the future development of our culture and associated values. Distributive justice is also clearly affected by copyright, as those without the necessary means cannot access copyrighted works. This not only lowers their welfare but also bars them from acquiring information necessary to improving their situation. ${ }^{25}$

To conclude, I believe (value-pluralist) consequentialism draws our attention to important concerns about copyright. I hope to have shown that it is very difficult to make a conclusive argument for copyright using such an approach, and there are strong indicators that consequentialism favours alternatives to the copyright system.

\section{Lockean approaches}

I will now turn my attention to those who lend their name to the French droit d'auteur and the German Urheberrecht: authors. ${ }^{26}$ How can their interests form a basis for the justification of copyright?

\footnotetext{
${ }^{22}$ Moore, A., 2011. Intellectual Property. In E. N. Zalta, ed. The Stanford Encyclopedia of Philosophy. Available at: http://plato.stanford.edu/archives/sum2011/entries/intellectual-property/ [Accessed June 6, 2013].

${ }^{23}$ Aigrain. Sharing: Culture and the Economy in the Internet Age, op. cit.

${ }^{24}$ Gillespie, T., 2007. Wired Shut: Copyright and the Shape of Digital Culture, Cambridge, MA: MIT Press, p.10.

${ }^{25}$ Murphy, D.J., 2012. Are Intellectual Property Rights Compatible with Rawlsian Principles of Justice? Ethics and Information Technology, 14(2), pp.109-121.

${ }^{26}$ These terms translate as author's rights.
} 
A successful account based on authorial interests is clearly insufficient for a conclusive judgement about the morality of copyright. Either authorial interests need to be balanced against the interests of the public or the account needs to be complemented by an argument dismissing the importance of public interests. However, it is clear that a successful authorial interest argument for copyright weighs heavily in favour of copyright regulations. Himma even thinks any justification of copyright "clearly depends on whether authors have a moral right in the content of their creations". ${ }^{27}$

Authorial interest theories come in a variety of guises. One prominent strand of thought is formed by those approaches that are based on Locke, and this is the focus of the present section ${ }^{28}$. I hope to show that Locke's original theory is fatally flawed when it comes to justifying copyright and that this flaw is inherited by later Lockean theories. John Locke's labour desert theory of material property can be divided into four main parts, which I will shortly sketch here.

According to Locke, God gave the earth to man in common, to be used to their advantage and convenience. ${ }^{29}$

(L1) Resources exist to be used by people.

For a person to enjoy the earth and what it produces, she must be able to exclude others from use of the good she desires. And in order to exclude others legitimately, a person must be the owner of that resource.

(L2) Enjoyment of a resource requires the ability to exclude others from using it; legitimate use requires ownership.

The fundamental question for Locke concerns how initial appropriation can come about. Locke's starting point is that human beings have ownership in themselves. This ownership extends not only to the body but also to the activities undertaken with it, inter alia labour. When working the land, people mix themselves, in the form of their labour, with the land. By mixing one's labour with the land, the land becomes an extension of the person and thereby the labourer's property.

(L3) People come to own a resource by mixing their labour with it.

The extent of the acquisition of property is however limited by two conditions. (L1) and (L2) postulate that resources are appropriated to be enjoyed - consequently appropriation that goes beyond what can be enjoyed is illegitimate. In this spirit, the

\footnotetext{
27 Himma. The Justification of Intellectual Property: Contemporary Philosophical Disputes, op. cit, p. 1152 .

${ }^{28}$ In legal theory the Lockean argument has found its expression in the sweat of the brow doctrine. It postulates that the effort or investment expended in the creation of a work warrants copyright protection. The sweat of the brow doctrine does not require that a work be creative in any way and is therefore mainly of historical importance. May, C. \& Sell, S.K., 2006. Intellectual Property Rights: A Critical History, Boulder, CO: Lynne Rienner Publishers.

${ }^{29}$ Locke, J., 1764. Two Treatises of Government, T. Hollis, ed., London, UK: A. Millar et al, bk. II, ch. V.
} 
first limitation states one may only acquire as much as one can use for oneself - if appropriation leads to waste it is not legitimate. Secondly, one may only acquire so much that there is enough and as good left for others after appropriation.

(L4) One may only acquire as much as one can use for oneself and only as long as there is enough and as good left for others.

Much criticism of Locke focuses on (L3) as it is not at all clear why mixing one's labour with a resource should lead to an extension of ownership rather than a loss. Nozick came up with the famous example of someone who throws a can of tomato juice into the ocean, asking whether this should really be enough to acquire ownership of the sea. ${ }^{30}$

Contemporary authors try to remedy this weakness by replacing the idea of the mixing of labour with other factors deemed morally relevant. Fisher argues that the expenditure of personal resources or effort gives rise to moral interests in the things that are thereby created. ${ }^{31}$ Himma proposes to see time as the crucial resource that is being used in authorial creation. ${ }^{32}$ Spinello argues that it is added value that matters. ${ }^{33}$ Nozick himself suppresses (L3) entirely and simply states that appropriation is legitimate up to the level proscribed by (L4). ${ }^{34}$

All these approaches focus on (L3) or (L4) while crucially leaving (L2) unchanged. But in the case of intellectual resources, it is simply not true that we need to exclude others in order to enjoy a resource. Copyright protects abstract types, not material tokens. If I write a book, I do not necessarily become the proprietor of the physical book I write - I might have stolen the paper - but rather am accorded copyright of the text contained therein, that is to say, in the meaningful combination of the symbols that comprise the text..$^{35}$ This means what is protected by copyright is non-rival. The same abstract authorial work can be used by an infinite amount of people, without anyone's enjoyment thereby being degraded. In the case of authorial works use does not require excluding others. Therefore appropriation is not necessary for legitimate use, and (L2) cannot be employed to justify the necessity to appropriate authorial works.

The argument so far is not new. Lockean theorists claim to be able to evade the above challenge concerning (L2) by letting (L3) do all the argumentative work. I agree that a variant of (L3) can possibly be used to argue why certain people come to have certain rights to a given resource or authorial work. Maybe creating something

\footnotetext{
${ }^{30}$ Nozick, R., 1974. Anarchy, State, and Utopia, Oxford, UK: Blackwell.

${ }^{31}$ Fisher, W., 2007. Theories of Intellectual Property. In S. Munzer, ed. New Essays in the Legal and Political Theory of Property. Cambridge: Cambridge University Press, pp. 168-199.

${ }^{32}$ Himma. The Justification of Intellectual Property: Contemporary Philosophical Disputes, op. cit.

${ }^{33}$ Spinello, R.A., 2003. The Future of Intellectual Property. Ethics and Information Technology, 5(1), pp.1-16.

${ }^{34}$ Nozick. Anarchy, State, and Utopia, op. cit.

${ }^{35}$ In fact, what is protected by copyright is not even the meaningful combination of symbols but some meaning of this combination of symbols. This explains why a translation of a work is also covered by copyright - even though the meaningful symbols are entirely different, the meaning of the symbols remains. The fact that meaning and expression cannot be easily differentiated is at the root of the difficulties regarding the idea/expression dichotomy.
} 
valuable does create rights. The crux of the matter however is that not only authors create value with regard to authorial works. In fact none of the proposals for (L3) is limited to authors. Someone can interpret an authorial work and add value, someone can laboriously copy it, or spend huge amounts of time carefully reading it. Without (L2) justifying why authors need to be able to exclude others from using their works, all these people should be accorded rights, too.

There are two steps to the problem. Firstly, the inapplicability of (L2) leads to the loss of an argument for one essential aspect of the notion of property: exclusivity. Secondly, all proposed replacements of (L3) fail at restricting rights to only those who create a work, namely those that we commonly consider to be authors. And this is why all Lockean theories fail. ${ }^{36}$

An objection to my argument is expressed by Spinello and Bottis. ${ }^{37}$ Their Lockean approach emphasises the idea that violating copyright harms owners. They base this argument on Locke's no harm principle. ${ }^{38}$ But what is the harm involved when a person uses another's work without their authorisation? Clearly, the harm in question cannot come from inability to enjoy the work - no such harm exists with non-rival authorial works. Could it be harm to the ability to monetise the work? As I have shown in the section on public interest accounts, copyright is neither very good at ensuring this ability nor does it provide the only way of monetising authorial works. Furthermore, we do not always protect people's ability to make money, and we would therefore need an argument why such protection is warranted in the case of authors. Nonetheless, I think the notion of harm is relevant to our case. I will explore this idea in the next sections but as you will see this means leaving Lockean theories behind.

The failure of Lockean theories holds a promise. If we find a morally valuable feature unique to authorship, we can let (L3) hold the whole argumentative weight without needing to be supported by (L2). This will furthermore enable us to see what harm authors may expose themselves to when publishing their works.

\section{Personality Interest}

Personality interest theorists think they know what feature of the creation of works gives rise to authorial interests, and they think this feature can take on all the argumentative weight. In this section I introduce the personality interest account, sketch how authors come to acquire such an interest, and argue why it merits being protected.

The personality argument under its many guises takes inspiration from Hegel ${ }^{39}$ and sometimes Kant ${ }^{40}$. What unites these approaches is the "idea that an individual enjoys an exclusive moral claim to the acts and content of his or her personality,

\footnotetext{
${ }^{36}$ Locke applied his theory only to material goods and can therefore not be blamed for the failure of Lockean theories on copyright.

${ }^{37}$ Spinello, R.A. \& Bottis, M., 2009. A Defense of Intellectual Property Rights, Cheltenham, UK: Edward Elgar.

${ }^{38}$ Locke. Two Treatises of Government, op. cit., bk. II, ch. II.

${ }^{39}$ For example : Hughes, J., 1998. The Personality Interest of Artists and Inventors in Intellectual Property. Cardozo Arts \& Entertainment Law Journal, 16, pp.81-181.
} 
personality being understood to include a variety of character traits, dispositions, preferences, experiences, and knowledge". ${ }^{41}$ Many authors stress the importance of external objects in people's quests for self-actualisation and for the development of their own personalities. ${ }^{42}$ In order to become who we want to be, to develop life plans and follow them through, we need to control external resources. Authorial works are crucial for personal self-actualisation and therefore merit being protected.

Personality interests are diverse and not exclusively authorial. Many people see for example their wedding rings as integral to their personalities. Therefore an authorial personality interest account needs to show what interests are specific to authors and why these trump other people's interests in authorial works.

What personality interests could be exclusive to authors? Hughes has three proposals: sourcehood interests, intentionality interests, and creativity interests. ${ }^{43}$ I will not discuss the first two ${ }^{44}$ as their scope is larger than what is protected by copyright. The third is however promising; creativity is an important aspect of the definition of the legal subject matter of copyright, and - as we will see - it is closely connected to our personality. In order to illustrate how creativity can underpin the moral justification of copyright, I will first explain what I mean by creativity, then shed some light on the connections between creativity, personal input, and personality interest.

The seminal case Feist Publications, Inc. v. Rural Telephone Service Co., decided by the US supreme court in 1991, illustrates the legal notion of creativity. The matter of contention was an alphabetical list of telephone numbers compiled by Rural, the entries of which were copied by Feist and published in their own telephone directory. Rural consequently sued Feist alleging copyright infringement, prompting Feist to challenge the copyrightability of the work in question. This question of copyrightability - and not the matter of copyright infringement - forms the core of the case. The US Supreme Court decided in Feist's favour, arguing that a simple alphabetical ordering of telephone numbers, as in Rural's directory, does not display any creativity and is therefore not copyrightable.

While Feist v. Rural is intuitively comprehensible, it is very difficult to put one's finger on what exactly makes something creative. I will rather inelegantly evade this problem and adopt Hughes (lack of an) explanation. Hughes states that in some cases we cannot ascribe an object's coming into existence to external factors, which we perceive as mechanistic or random. ${ }^{45}$ In these cases a person is responsible for

\footnotetext{
${ }^{40}$ For example : Lucibella, C., 2010. Filesharing and Ownership of Digital Objects: Intellectual Property according to Kant's Theory of Possession. Theoretical and Applied Ethics, 1(1), pp.35-40.

${ }^{41}$ Himma. The Justification of Intellectual Property: Contemporary Philosophical Disputes, op. cit., p.1155.

${ }^{42}$ ibid. Hughes. The Personality Interest of Artists and Inventors in Intellectual Property, op. cit. Rawls, J., 2000. Lectures on the History of Moral Philosophy B. Herman, ed., Cambridge, MA: Harvard University Press. Resnik. A Pluralistic Account of Intellectual Property, op. cit.

${ }^{43}$ Hughes. The Personality Interest of Artists and Inventors in Intellectual Property, op. cit.

${ }^{44}$ Sourcehood interest denotes the interests we may have in objects when we have been implicated in the causal chain of events that has brought them into existence. Intentionality interests are interests in objects that we have intentionally brought into existence.

${ }^{45}$ ibid.
} 
creating said object because this person's personal input explains why the object has come into existence. In the following, I will simply assume that personal input exists and that a certain degree of it is necessary to call an activity and the product thereof creative. Let us furthermore assume that creativity adequately tracks who is to count as an author, that is to say, that an appropriate level of personal input defines creativity, which in turn defines what is an original work and who is an author.

So far I have linked authorship to creativity and creativity to personal input. However, the connection between personal input and personality interest still needs to be explicated. Authors are divided on whether personal input necessarily implies involvement of the author's personality. Some authors, such as Dewey ${ }^{46}$, claim that all creative endeavours are marked by our interests, whereas others, such as Hughes ${ }^{47}$ argue that some authors create original works without these being connected to their personality. We need not resolve this matter; even the latter approach does not endanger a personality interest argument for copyright. A proponent of copyright can argue that those cases in which authors do form personality interests are of such importance that they merit offering copyright protection to all those who might potentially benefit from it. Summarising the argument thus far, personal input is what makes works creative and this personal input - at least regularly - leads to the author's personality being extended to, or expressed in, the works they create. ${ }^{48}$

Hughes identifies two potential objections to the authorial personality interest account: "[i]t may be wrong for people to (1) identify with their capacities; and then, (2) identify with the intellectual products of those capacities". ${ }^{49}$ I do not believe it can be wrong for people to identify with their capacities. Individual personal capacities are an essential part of who we are. What is more, also our moral and political convictions and our intimate fears and hopes can be expressed in what we create. To demand that people not identify with these elements of their personalities is tantamount to asking them not to identify with themselves. This is both impossible and morally wrong.

But why should these personality interests extend to authors' creative works? Hughes argues that this is the case because our productive life - the sense of imprinting ourselves on the outside world - is essential for our self-actualisation. ${ }^{50}$ And because an author's ability to develop herself can be harmed when other people use or modify her works, authors deserve to see their interests protected.

\section{Regulating authorial works}

Consequentialism and personality interest accounts shed light on the moral

\footnotetext{
${ }^{46}$ Dewey, J., 1980. Art as Experience, New York: Perigee Books.

${ }^{47}$ Hughes. The Personality Interest of Artists and Inventors in Intellectual Property, op. cit.

${ }^{48}$ The idea of an extension of personality also shows that personality interest approaches should not be seen as entirely unrelated to Lockean approaches. In fact it is possible to interpret Locke in a way that renders his theory to a large extent compatible with a personality interest theory. Hughes quoting Rapaczynski - writes that: "[s]ome writers have suggested that Locke actually subscribed to such a personality theory in which 'applying one's labor to a natural object ... endow[s] it with certain features pertaining to one's own form of existence'". ibid., p.28.

${ }^{49}$ ibid., p.84.

50 ibid.
} 
interests authors and the public may have in authorial works. In the remainder of the paper, I want to explore a minimal set of principles that protect these morally valuable interests and argue why these are sufficient.

Attribution: authors have the right to be attributed as the authors of their works if doing so is possible with reasonable expenditure of resources.

Attribution ensures that people are recognised for being authors, which can in itself be a valuable recognition of people's agency. ${ }^{51}$ Moreover, without attribution it is difficult for authors to gain reputation, which functions as an important form of social recognition. Human beings are social animals, and without social recognition most people will fail in their quests for self-actualisation. Social recognition is also connected to access to material and social resources that are essential to further selfactualisation.

Attribution does not generally hinder the public's ability to freely use, modify, and distribute authorial works. The right of attribution also incentivises authors to produce works and in that sense advances the public interest. Moreover, society would be hard-pressed to support and recognise important contributions without knowing who contributed what. However, the public interest in identifying authors does not justify an obligation to attribute authorial works. Being able to publish works anonymously can be tremendously important, be it for personal, political, or artistic reasons. Should authors be able to waive the right of attribution? If authors are not obliged to use their right of attribution, then I would follow a liberal argument and claim they should be able to permanently waive that right as well.

The public must try to attribute works correctly, which may involve developing schemes that facilitate locating authors and attributing works correctly. However, if, after expenditure of a reasonable amount of resources, it still proves impossible to correctly attribute a work, then the public interest trumps the authorial interest and the work may be used without attribution. ${ }^{52}$

Whether authors should be able to transfer their right of attribution is a delicate matter. On the one hand, an author may be part of a collective desiring to publish a work as a unified entity. Here, I believe transferring the right of attribution is justified. On the other hand, there are instances where an author may want to transfer a work to some person who is disconnected from the production of the work. In this second case I see transfer as illegitimate, principally because of the public's interest in not being deceived about who produced a given work. The difficulty consists in these two cases not always being easily distinguishable.

Non-endorsement: authors have the right of having it clearly stated that a use or modification of their work is not endorsed or approved by them.

People who use others' authorial creations must make it clear that their use

\footnotetext{
51 ibid.

${ }^{52}$ Otherwise use of works would be very restricted in practice. A user may for example be unable to locate the author of a work because the necessary records do not exist or are very difficult to access. Works can also be based on so many prior works that it becomes infeasible to attribute them all.
} 
does not necessarily signify endorsement by the original author. Otherwise it might be thought that the uses or modifications undertaken were approved by the original author, and this can illegitimately reflect back on them. This right complements the right of attribution and protects authors' correct social recognition. This right should have no impact on the public's ability to use a work. A user does not even need to know a work's author in order to include a notice saying its author does not necessarily endorse her use of it. Indeed, if it were generally known that use of a work does not imply endorsement, including such notices might become unnecessary.

Profit sharing: authors have the right to a fair share of the profits made from commercial exploitation of their works.

Profit sharing has the potential of benefiting authors without damaging public interest. The share of the profits given to authors should be such that commercial use is not unduly restricted and non-commercial use not affected at all. ${ }^{53}$ To ensure that authors cannot unduly leverage this principle, the share should not be subject to negotiations between the author and the commercial user but set beforehand by a competent institution. Such a profit sharing rule should incentivise the production of authorial works without negatively impacting the public's ability to use, modify, and share authorial works. This right is also in the interests of authors. They gain an additional means of income and recognition, and their works are protected from being used to the exclusive financial benefit of others.

For how long should we protect the three rights I have described so far? I do not know. I believe this matter depends on the structure of the overall legal system, on the economic situation and system, and other factors. I do not however believe that the protection should ever be longer than the life of the author. Authors' personality interests extinguish with their deaths, and it is dubious whether longer-than-life terms of protection provide any additional incentives to authors.

Alternative compensation systems: authors should be fairly compensated for their work.

Profit sharing alone might not be able to provide sufficient financial incentives to authors. Moreover, authors should be compensated for their contributions to society and given the means necessary to lead decent lives. At least the latter two of these matters are not specific to authors; they are concerns about fairness and social justice, which apply to everyone. When designing alternative compensation systems, care should be taken to ensure they fulfil their twin goals of providing financial incentives and enabling a decent life for authors.

I believe these four principles suffice. Additional economic rights are unwarranted from a public interest perspective if authors' income and financial incentives are guaranteed by profit sharing and alternative compensation systems and if such rights negatively affect public interests. I believe this is the case at least for all the classical economic rights. From a personality interest perspective, Radin has

\footnotetext{
${ }^{53}$ I gloss over a significant difficulty here insofar as it is not always easy to distinguish commercial from non-commercial uses.
} 
argued that property rights are a means of recognising authors for their important contributions. ${ }^{54}$ Not giving this point the discussion it deserves, I will only state that I think there are more valuable forms of recognition that we should espouse instead.

Possible additional moral rights require a more detailed discussion. Authors may, for example, be associated with uses of their works even when a nonendorsement notice is included. This risk is real; however, the danger is minor and no worse than in the copyright system. Firstly, most people should take a nonendorsement clause at face value. Secondly, the danger of an author's unjustified association with uses of her work diminishes when authors have less control over their works. When authors have a high level of control over their works, not exercising their rights can more plausibly be interpreted as endorsement as when authors lack any ability to control their works. Thirdly, copyright itself cannot ensure that an author is never unjustifiably associated with uses of her works. One cannot prohibit people from thinking certain thoughts, and there always exists the possibility of some people making unjustified associations between authors and uses of their works. Finally, it is not always unjustified to associate an author against her will with a certain use of her work.

An author may also feel that she loses her ability to express herself when others use her creations in ways she dislikes or even abhors. This may stop her from trying to publicly express herself, which can endanger her capacity for selfactualisation. Sometimes this situation is conceived of as a conflict between competing personality interests: on the one hand there is the author and on the other the user who tries to give the work a new meaning. Yet, such a conflict is not necessary as is evidenced by the many authors who renounce the right to control their creations and who indeed see this as furthering their personality interests. ${ }^{55} \mathrm{I}$ believe whether or not authors are hurt in this sense by certain uses of their works depends on the attitudes they have towards their works. If an author does not believe she owns the work in question, if she understands that she's not the sole source of its meaning, if she is tolerant of other views, and if she sees authorial works as building on a cultural commons, then uses she dislikes are less likely to endanger her quests for selfactualisation.

Authorial works created by others play important roles in our lives and are often integral to our personality development. Many of us have probably been significantly influenced by some of the books we read, and it is not uncommon for this influence to be so strong that it helps define who we are. A person may want to share with others works they feel express their personalities. In other cases, authorial works need to be adapted to best suit the individual's expressive desires. Both modification and distribution may however not be possible since copyright per default prohibits such uses. Copyright protection therefore often negatively impacts others' -

\footnotetext{
${ }^{54}$ Radin, M.J., 1982. Property and Personhood. Stanford Law Review, 34(5), pp.957-1015.

${ }^{55}$ One example is the importance given by the hacker ethics to not restricting access to works and information. This is a fundamental part of the hacker identity and evidenced by Free Software.

Another example are the hugely popular Creative Commons licenses with which authors can forgo most of the rights accorded by copyright. For instance Flickr, an image hosting website, holds 350 million photos with such a license. Chaos Computer Club, CCC / Hackerethik. Available at: https://www.ccc.de/de/hackerethik [Accessed January 11, 2016]. Flickr, Flickr: Creative Commons. Available at: https://secure.flickr.com/creativecommons/ [Accessed January 11, 2016].
} 
both authors' and non-authors' - ability for self-actualisation and "systemically prevent[s] prospective personhood interests from developing" (emphasis in the original). ${ }^{56}$

Forms of authorial self-actualisation that build on copyright and thus endanger others' quests for self-actualisation can also be seen as noxious and not morally valuable. If this is correct, hurting the public would also be harmful to authorial personality interests. Radin for example argues that appropriation is "healthy" conducive to valuable self-actualisation - only in those instances where it does not harm others. ${ }^{57}$ And in the case of copyright, harming others cannot be escaped without renouncing one's rights, at least as long as some rights cannot be acquired or some people lack the necessary financial means therefor.

Both public interest and personality interest accounts show that copyright necessarily has negative effects on the public, whereas the effects on authors are neither inevitable nor clearly positive or negative in character. I have also argued that the possible negative effects on authors, stemming from unauthorised use or modification of their works, depend on their attitudes towards their works. Renouncing the control over one's works can even constitute a valuable part of authorial personality. Therefore, if it is possible to change authors' attitudes towards their creations - which I believe it is - then it is better to bring about such a change than to insist that the public must be harmed.

\section{Contributors}

Until now I have analysed two types of interests: authorial interests and public interests. These two do not however exhaust all the possible moral interests people have in authorial works. In this section I explore interests of contributors - people who are not authors but more involved in the production of works than the public.

Copyright has a place for at least some contributors, regulating authorial rights in joint or collective works. ${ }^{58}$ If I contribute a paragraph to a novel, the novel's author does not hold the copyright in the paragraph in question; this copyright is mine. She instead holds the copyright in the creative ordering of the different parts of the book as well as in those parts of the book she authored.

Not every type of contribution benefits from copyright protection. Firstly, some contributions are considered too insubstantial or too small to be protected. Secondly, and more importantly, there are contributions that are far from insubstantial that also lack protection. For instance, film directors often obtain the copyright and moral rights in a film, even though there are many others whose contribution is far from negligibly small. Another example is the master craftsman who fashions a statue according to an artist's plans and who does not profit from any copyright protection either.

\footnotetext{
${ }^{56}$ Hughes. The Personality Interest of Artists and Inventors in Intellectual Property, op. cit.

${ }^{57}$ Radin. Property and Personhood, op. cit.

${ }^{58}$ A collective work consists of multiple separable parts authored by different parties whereas one speaks of a joint work when the individual contributions to a work cannot be separated from each other. See for example : Colston, C., 1999. Principles of Intellectual Property Law, London, UK: Cavendish.
} 
It could now be argued that these contributors do not make the cut because they lack creativity - they merely implement another person's creative idea. While the truth of this is questionable, protecting contributors does not even require them to be creative. The various approaches that failed to ground copyright because they applied not only to authors might justify interests for contributors. It might for example be argued that the effort that contributors expend gives rise to moral interests. It might also be reasoned that contributors are justified to personally identify with the creation of others' authorial works because they have intentionality personality interests in the work. These personality interests are connected to our intentional actions and their importance for a person's sense of agency. ${ }^{59}$

We have seen in earlier sections that personal input and thus creativity are a matter of degree, and it is therefore difficult to argue why there should be a concrete cut off point below which no rights at all should be accorded. The difference between authorial and contributors' interests is one of degree. It is very difficult to say when a contribution becomes sufficiently creative to merit being called an authorial work on its own. This leads me to agree with Hilpinen who argues that it is "possible to distinguish degrees of authorship" (emphasis original). ${ }^{60}$ These degrees of authorship could then be accompanied by degrees of rights.

Would the existence of contributors' moral interests imply that we should extend the range of people to whom copyright is accorded? I do not think so for a simple reason, which I will not however flesh out here: contributors' personality interests are likely to be less strong than authors' and according copyright to contributors could harm the general public by further complicating the legal situation. Therefore, if authors' should only be granted very limited exclusive rights, then the case is even more clear-cut with contributors.

I believe contributors' interests could lead us to espouse new ways of attribution that give recognition also to those who are now invisible. One interesting approach can be seen in Free Software projects, which are often hosted on platforms Version Control Systems - that record all the changes made to the source code. Every contribution is publicly recorded and usually attributable to a specific person. One can easily find out whether a specific contribution is substantial or not and appraise its value. By attributing every contribution, such systems render it less important who is an author and who a contributor, stressing instead the collective nature of creativity.

\section{Conclusion}

Valid authorial and public interests in authorial works exist. However, Lockean approaches cannot even in principle justify exclusive authors' rights. While consequentialist as well as personality interest theories can do so, they also fail to justify copyright. What consequentialism and personality interests do justify is the limited set of rights I have presented towards the end of this paper. In addition, I have argued that we might need to think of ways to protect the interests of contributors.

\footnotetext{
${ }^{59}$ Hughes. The Personality Interest of Artists and Inventors in Intellectual Property, op. cit.

${ }^{60}$ Hilpinen, R., 2011. Artifact. In E. Zalta, ed. The Stanford Encyclopedia of Philosophy. Available at: http://plato.stanford.edu/archives/win2011/entries/artifact/ [Accessed November 29, 2013], sec. 4.
} 
This paper has tried to present an overall view of the ethics of copyright. I have done so because I believe only a pluralist account can allow for judgements on copyright's moral status. Unfortunately this meant leaving by the wayside many of the details of the argument. A first inadequacy is that the moral foundations grounding the interests I have argued for were to a large extent absent. How exactly are authorial works important for self-actualisation? What values should a consequentialist account take into consideration? I have also mentioned the importance of authors' attitudes towards their works without giving this much thought. Virtue ethics, which I have also ignored, might help in investigating the attitudes authors should hold towards their works. ${ }^{61}$ This last point deserves emphasis: we need more research on the nature and value of the relationship between authors and their works.

I also had to leave aside many additional arguments in favour of my view on copyright. Above all, the rich literature on the value of the commons and of collaborative creative processes comes to mind. In general, my paper has focused perhaps too heavily on the individual, disregarding to what extent culture and knowledge production are social processes.

My analysis has focused on copyright law. A more complete investigation of the ethics of authorial works would have to cover additional questions. Not all of the moral issues surrounding authorial works are codified and these non-legal areas would need to be considered, too. I have also not treated the question of when authors should - or must - publish works or refrain from doing so. Finally, copyright interrelates with other spheres of intellectual property - patents and trademarks - and these interrelations deserve to be analysed.

I hope to see more, and more expansive, pluralist analyses of the ethics of authorial works. The significance of copyright can hardly be understated as it shapes one of the defining aspects of our humanity: our culture. Given these stakes, I have no doubt that copyright will remain a domain of heated debates for many years to come. We need more than that however - we need honest efforts at mutual understanding and constructive criticism. My hope is that moral philosophers will help making this extremely important discussion a fruitful one.

\footnotetext{
${ }^{61}$ See for example : Benkler, Y. \& Nissenbaum, H., 2006. Commons-based Peer Production and Virtue. Journal of Political Philosophy, 14(4), pp.394-419.
} 
Int. J. Arts and Technology, Vol. ?, No. ?, 2016 